\title{
Drivers for and against municipal wastewater recycling: A review
}

\author{
Authors: Nadja C. Kunz ${ }^{1 *}$, Manuel Fischer ${ }^{1,2}$, Karin Ingold ${ }^{2,1}$, Janet G. Hering ${ }^{1,3,4}$ \\ 1. Swiss Federal Institute for Aquatic Science and Technology (Eawag), Überlandstrasse 133, CH-8600 \\ Dübendorf, Switzerland \\ 2. The University of Bern, Switzerland \\ 3. IBP, Swiss Federal Institute of Technology (ETH) Zürich, CH-8092 Zürich, Switzerland \\ 4. ENAC, Swiss Federal Institute of Technology Lausanne (EPFL), CH-1015 Lausanne, Switzerland \\ * Corresponding author: nadjakunz1@gmail.com
}

\begin{abstract}
The reclamation, treatment and reuse of municipal wastewater can provide important environmental benefits. In this paper, 25 studies on this topic were reviewed and it was found that there are many $(>150)$ different drivers acting for and against wastewater recycling. To deal with the challenge of comparing studies that entailed different research designs, a framework was developed which allowed the literature to be organized into comparable study contexts. Studies were categorized according to the level of analysis (wastewater recycling scheme; city; water utility; state; country; global) and outcome investigated (development/investment in new schemes; program implementation; percentage of wastewater recycled; percentage of water demand covered by recycled water; multiple outcomes). Findings across comparable case studies were then grouped according to the type (for or against recycling) and category of driver (social, natural, technical, economic, policy or business). The utility of the framework is demonstrated by summarizing the findings from four Australian studies at the city-level. The framework offers a unique approach for disentangling the broad range of potential drivers for and against water recycling and to focus on those that seem relevant in specific study contexts. It may offer a valuable starting point for building hypotheses in future work.
\end{abstract}

Keywords: water recycling; wastewater reuse; systems analysis; Australia 


\section{INTRODUCTION}

Worldwide, freshwater availability is dwindling, leading to a search for new water sources and necessitating improved efficiencies across the urban water cycle (Brown et al., 2009; Ferguson et al., 2013a). The reclamation, treatment and reuse of municipal wastewater for productive purposes including agriculture, industry and domestic uses (hereafter referred to as "water recycling") are recognized as part of the solution for increasing available water supplies, especially in water scarce areas (Chen et al., 2013).

Understanding the drivers for and against water recycling can facilitate efforts to meet associated policy goals. For example, in Europe the Urban Wastewater Treatment Directive (91/271/EEC) advises water reuse "where appropriate" but does not define "appropriateness" (Hochstrat et al., 2006). Similarly, in 2007 the Australian federal government set a national target to recycle 30\% of Australia's wastewater by 2015 (Marsden Jacob Associates, 2008) but did not articulate selection criteria for prioritizing investments. Given the lack of clear criteria, many different factors can influence whether water recycling actually happens or not.

Although water scarcity is often cited as an important driver towards water recycling, it is insufficient to explain differences in the percentage and volume of water recycled across cities, regions, and countries (Hochstrat et al., 2010; Kunz et al., 2015; Radcliffe, 2010; Yüce et al., 2012). Research in the US (Bischel et al., 2012) and Australia (ISF, 2013) has identified a diverse array of economic, institutional, ecological, technological and sociological drivers that can influence the success of government programs to develop new recycling schemes.

The objective of this review is to compare previous literature and propose directions for future research. We begin by comparing 25 previous studies and highlight differences in research design. A framework is developed which provides a basis for organizing the literature according to comparable study contexts and allows synthesis of the drivers for and against recycling. The utility of the framework is demonstrated by applying it to summarize the results from four Australian studies conducted at the city scale.

\section{RESEARCH DESIGN IN THE SURVEYED LITERATURE}

Of the 25 articles selected for this review, 14 focus on the Australian context and the remaining 11 investigate international trends or consider cases within Europe, the US, and the Middle East. These articles were identified during a larger research project which focused on Australia (Kunz et al., 2015). A structured literature search was used to select the Australian articles (see S1 in Supplementary Material, available online at http://www.iwaponline.com). Australia represents a compelling study context because water recycling has been promoted by federal and state/territory governments, which has been accompanied by an increase in the percentage and volume of water recycled in major capital cities over the last decade (Radcliffe, 2010). Table 1 summarizes statistics about the research designs across the 25 studies; similarities and differences are subsequently discussed. 
Table 1. Research design of the 25 articles analyzed in this review. See Supplementary Material for details, available online at http://www.iwaponline.com. (S2) presents the details for each study analyzed, while (S3) describes the categories used for comparison.

\begin{tabular}{|l|r|}
\hline Number of cases & \\
Single case (1) & 11 \\
Small-N (2-5) & 3 \\
Medium-N (6-20) & 6 \\
Large-N (>20) & 3 \\
N/A & 2 \\
\hline Method of data collection & \\
Interviews and/or direct observations (assumed) & 8 \\
Interviews and/or direct observations (explicit) & 3 \\
Literature review and/or secondary data analysis & 8 \\
Research method not clearly stated & 4 \\
Survey & 2 \\
\hline Level of analysis & \\
Water recycling scheme & 6 \\
City & 7 \\
Country & 5 \\
Region & 4 \\
Global & 2 \\
Multiple scale analysis & 1 \\
\hline Method of data analysis & 18 \\
Qualitative & 3 \\
Quantitative & 4 \\
Descriptive & 19 \\
\hline Outcome investigated & 1 \\
Development of and/or investment in new schemes & 1 \\
Program implementation & 2 \\
Percentage and/or volume of wastewater recycled & 1 \\
Percentage of water demand that is covered by recycled water & 15 \\
Different types of outcome & 4 \\
\hline Type of beneficial use for recycled water & 6 \\
Various & \\
Irrigation & \\
Industrial & \\
Potable & \\
\hline Types of drivers identified & \\
Drivers for recycling & \\
Barriers against recycling & \\
Drivers for and against recycling & \\
\hline
\end{tabular}

\section{Number of cases}

The large majority of studies entailed single case studies, and only three studies involved large-N research designs with over 20 cases (Bischel et al., 2012; Bixio et al., 2006; Lazarova et al., 2000). Two studies did not focus on specific cases, but rather discussed general trends in water recycling drawing on international experiences from several countries globally (Asano, 2005; Chen et al., 2013). 


\section{Method of data collection}

A limitation of the 25 articles is that almost half lacked information on how data were collected. For eight studies, authored by consultants (Apostolidis et al., 2011; Freeman et al., 2008; Traves et al., 2008) or representatives from government departments (Anderson, 2006; Kracman et al., 2001), we assumed that data were obtained from interviews and/or direct observations. Of the studies that did state the research method, eight relied on data collected via a literature review and/or analysis of secondary data. Online survey questionnaires with water utility managers (without accompanying fieldwork) were used in two studies (Bischel et al., 2012; Muston and Wille, 2006). The reliance on literature reviews, secondary data and online questionnaires was often associated with large- $\mathrm{N}$ research designs.

\section{Level of analysis}

Studies can also be distinguished according to the level of analysis. Numerous studies have investigated the drivers for and against water recycling at the level of water recycling schemes (Apostolidis et al., 2011; Bischel et al., 2012; Bixio et al., 2006; Chanan et al., 2011; Hermanowicz et al., 2001; Institute for Sustainable Futures, 2013; Kracman et al., 2001; Muston and Wille, 2006). Cities are another common level analyzed (Anderson, 2006; Arbon and Ireland, 2003a; Chang et al., 2013; Giurco et al., 2011; Hurlimann and Dolnicar, 2010; Radcliffe, 2010). At the regional level, authors have studied major water recycling projects seeking to ensure water supply security at the state level, e.g. Queensland (Freeman et al., 2008; Traves et al., 2008). Others have shown the benefits of water recycling projects for achieving regional industrial synergies between wastewater treatment plants and minerals processing sites (van Beers et al., 2007b). At the country level, historical accounts describe conditions promoting recycling within countries (Barbagallo et al., 2001; Radcliffe, 2006), while comparative studies correlate hypothesized drivers (e.g. rainfall characteristics) with differences in water recycling performance between countries (Hochstrat et al., 2008; Hochstrat et al., 2006). Two studies (Asano, 2005; Chen et al., 2013) discuss global drivers towards water recycling.

\section{Method of data analysis}

With the mainly small-N research designs, a qualitative and/or descriptive approach was the predominant method of data analysis. Only three studies adopted a statistical approach (Bischel et al., 2012; Chang et al., 2013; Hochstrat et al., 2006). Hochstrat (2006) conducted a correlational analysis between 18 European countries to investigate the relationship between water stress (measured by consumptive water use intensity) and the extent of water reclamation/reuse. Chang et al. (2013) used a stepwise regression to investigate the extent to which four factors influence wastewater reclamation and reuse in 11 Chinese cities.

\section{Outcome investigated}

There were clear differences in the outcomes investigated, which can be assigned to five types: (1) development/investment in new schemes; (2) program implementation; (3) percentage of wastewater recycled; (4) percentage of water demand covered by recycled water; and (5) several outcomes. The most frequent outcomes analyzed were the investment/development in new schemes (11 studies) or investigation of several outcomes (10 studies). 


\section{Type of beneficial use of recycled water}

Most studies considered the use of recycled water for a range of applications, although a handful of studies focus on one type of use, e.g. irrigation (Barbagallo et al., 2001; Chanan et al., 2010) or industrial (Giurco et al., 2011; van Beers et al., 2007a).

\section{Types of drivers identified}

A common observation across studies was a tendency to focus on the drivers for (15 studies), rather than against (four studies), water recycling. Only six studies jointly considered drivers for and against recycling (Arbon and Ireland, 2003b; Bischel et al., 2012; Giurco et al., 2011; Kracman et al., 2001; Radcliffe, 2006; van Beers et al., 2007a).

\section{AN ORGANIZING FRAMEWORK TO CATEGORISE PREVIOUS RESEARCH AND COMPARE STUDY FINDINGS}

Reviewing the findings across the 25 studies revealed over 150 drivers that may influence wastewater recycling (89 for and 71 against, see Supplementary Material, available online at http://www.iwaponline.com). In some studies, drivers were explicitly stated, however many studies entailed a general discussion about the evolution of water recycling. For these studies, we derived the drivers/barriers through interpreting the conclusions from the text. With such a large number of drivers, it proved difficult to compare/ contrast studies directly. We also observed that differences in research design may influence which drivers are identified as important. To facilitate further comparison of study findings, we therefore developed an organizing framework (Figure 1) to firstly distinguish between study contexts, and to secondly distinguish study findings.

\section{STEP 1. DISTINGUISHING STUDY CONTEXTS

\begin{tabular}{cc}
\hline & \\
Same level of analysis? & Same outcome investigated? \\
- Recycling scheme & - Development of and/or investment in new schemes \\
- City & - Program implementation \\
- Water utility & - Percentage of wastewater recycled \\
- State & - Percentage of demand covered by recycled water \\
- Global & - Several outcomes were examined
\end{tabular}

STEP 2. DISTINGUISHING STUDY FINDINGS

Type of driver
- Driver for recycling
- Driver against recycling

$$
\begin{aligned}
& \text { Category of driver } \\
& \text { - Social } \\
& \text { - Policy } \\
& \text { - Technical } \\
& \text { - Natural } \\
& \text { - Economic } \\
& \text { - Business }
\end{aligned}
$$

Figure 1. Overarching framework to facilitate the comparison of study findings across contexts 


\section{Distinguishing study contexts: level and outcomes analyzed}

We focus on two aspects of study design that we regard as having the greatest influence on the comparability across studies. First, recognizing that the drivers influencing behavior in complex systems operate across different spatial and temporal scales (Allen and Starr, 1982; Salthe, 1985), we contend that studies should only be compared if they are conducted at the same level of analysis (Figure 2). The importance of scale for explaining behavior in complex, nested systems has been recognized in other fields, where scale (level) has been used to develop organizing frameworks (Kunz et al., 2013; Moran and Kunz, 2014; Ostrom, 2007). Next, we argue that studies should only be compared if they investigate the same outcome. Our framework distinguishes between the five outcomes identified during this review: development of and/or investment in new schemes; program implementation; percentage of wastewater recycled; percentage of water demand covered by recycled water; and multiple outcomes. Many of the analyzed studies neglected to specify the outcome(s) examined; we consider it advisable that this information be provided in future studies.

\section{Distinguishing study findings: category and type of driver}

Having identified studies conducted in the same study context (which are thus comparable), the study findings can also be organized into types and categories. First, the drivers for and against recycling should be distinguished because these were found to be non-symmetric even within the same study context (Arbon and Ireland, 2003b; Bischel et al., 2012; Giurco et al., 2011; Kracman et al., 2001; Radcliffe, 2006; van Beers et al., 2007a). For example, in Bischel et al. (2012)'s study of recycled water programs in California, the three most important drivers for recycling (wastewater discharge requirements; water supply needs; local/regional/state policy and mandates) differed from those against (economic/financial disincentives; perceptions and social attitudes; who pays system costs). It is also useful to aggregate drivers into higher-level categories, because other authors have shown that this can facilitate the interpretation of study findings (Bischel et al., 2012; van Beers et al., 2007a). Our framework distinguishes between six categories - social, policy, technical, natural, economic and business. 


\begin{tabular}{|c|}
\hline $\begin{array}{r}\text { Level } 6 \\
\text { Global }\end{array}$ \\
\hline Global \\
\hline
\end{tabular}

Figure 2. Urban water systems represent decomposable complex systems and can thus be organized across different levels. For example, Sydney Olympic Park (water recycling scheme) is one of several schemes servicing Sydney (city). The Sydney Water Corporation (water utility) operates a total of 16 wastewater treatment plants which service Sydney and the surrounding regions of Illawarra and the Blue Mountains. These regions lie within New South Wales (state), Australia (country). Note that the proposed scales of organization will not apply in every context (e.g. water utilities are not always larger than cities). Layout of the framework inspired by Kunz et al. (2013). Images of Australia were produced in ArcMap 10.1 using datasets obtained from the Australian Standard Geographical Classification (ASGC) Digital Boundaries (Australian Bureau of Statistics, 2011). 


\section{APPLICATION OF THE FRAMEWORK}

To demonstrate the utility of the framework, we apply it to analyze the 25 studies included in this review. When the studies are grouped according to the level of analysis and the outcome examined (Table 2; see Supplementary Material for details, available online at http://www.iwaponline.com), it is clear that previous literature has focused on the development of and/or investment in new schemes (16 studies). Three levels were examined with about equal frequency, with four studies each at the levels of water recycling scheme, city and region. Gaps in current research can also be seen in Table 2; for example, no studies were conducted at the level of water utilities. Generally, studies that focused at higher levels (country or global) lacked specificity regarding the outcome investigated - either several outcomes were considered or the outcome was not defined.

Table 2. Studies ${ }^{\S}$ can be compared according to the scale of analysis and outcome investigated. Shaded cells indicate dominant study contexts, whereby darker shading indicates a greater number of studies. White cells indicate study contexts that were not analyzed.

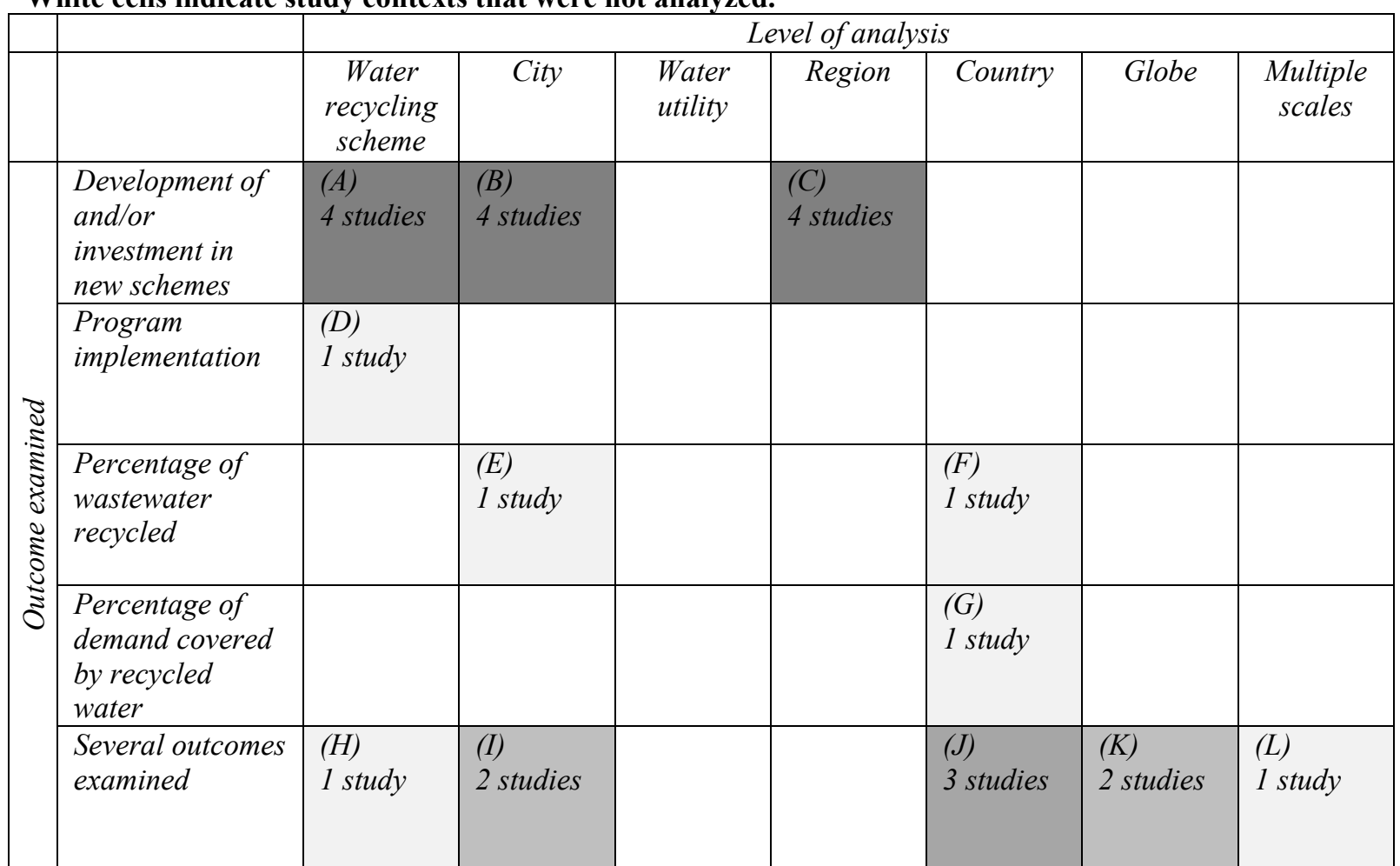

$\$$ (A) (Hermanowicz et al., 2001; Institute for Sustainable Futures, 2013; Kracman et al., 2001; Muston and Wille, 2006); (B) (Anderson, 2006; Chanan et al., 2011; Giurco et al., 2011; Hurlimann and Dolnicar, 2010); (C) (Freeman et al., 2008; Traves et al., 2008; van Beers et al., 2007b; Yüce et al., 2012); (D) (Bischel et al., 2012); (E) (Chang et al., 2013); (F) (Hochstrat et al., 2006); (G) (Hochstrat et al., 2008); (H) (Apostolidis et al., 2011); (I) (Arbon and Ireland, 2003a; Radcliffe, 2010); (J) (Barbagallo et al., 2001; Lazarova et al., 2000; Radcliffe, 2006); (K) (Asano, 2005; Chen et al., 2013); (L) (Bixio et al., 2006).

Based on this categorization, findings can be compared for studies conducted at the same level and that examined the same outcomes. As an example, this is demonstrated by comparing the four studies of Australian cities that investigated the development of and/or investment in new recycling schemes (case B). Three of the four studies discussed drivers for (Anderson, 2006; Chanan et al., 2011; Giurco et al., 2011), while two discussed drivers against (Giurco et al., 2011; Hurlimann and Dolnicar, 2010) recycling. Natural and policy drivers were cited most frequently - drought and/or water scarcity was identified in three studies (Anderson, 2006; Chanan et al., 2011; Giurco et al., 2011), while water reforms to 
improve river health and/or increase the cost of water discharge was identified in two studies (Anderson, 2006; Giurco et al., 2011). Interestingly, natural drivers were cited as important for but not against recycling.

Table 3. Study findings from the four Australian studies conducted at the city level that investigated the development of and/or investment in new recycling schemes (Level 2 of the framework in Figure 1)

\begin{tabular}{|c|c|}
\hline Drivers for recycling & Drivers against recycling \\
\hline $\begin{array}{l}\text { Social drivers: } \\
\text { - } \quad \text { Population pressures (Chanan et al., 2011) } \\
\text { Economic drivers: } \\
\text { - Water price security for users of recycled water } \\
\text { (Giurco et al., 2011) } \\
\text { Business drivers: } \\
\text { - Corporate sustainability focus by industrial water } \\
\quad \text { users (Giurco et al., 2011) } \\
\text { Policy drivers: } \\
\text { - Water reforms to improve river health and/or } \\
\text { increase costs of water discharge (Anderson, } \\
\text { 2006; Giurco et al., 2011) } \\
\text { Technical drivers: } \\
\text { - } \quad \text { Ageing infrastructure (Chanan et al., 2011) } \\
\text { Opportunity to link with cogeneration on } \\
\text { industrial sites (Giurco et al., 2011) } \\
\text { Natural drivers: } \\
\text { Drought and/or water scarcity (Anderson, 2006; } \\
\text { Chanan et al., 2011; Giurco et al., 2011) }\end{array}$ & $\begin{array}{l}\text { Social drivers: } \\
\text { - Public opposition to recycling (Hurlimann and } \\
\text { Dolnicar, 2010) } \\
\text { Economic drivers: } \\
\text { - Higher cost for recycled water compared with } \\
\text { other options (Giurco et al., 2011) } \\
\text { Business drivers: } \\
\text { - Cultural challenges within a company (Giurco et } \\
\text { al., 2011) } \\
\text { Changing industry presence in area (less heavy } \\
\text { industry) (Giurco et al., 2011) } \\
\text { Policy drivers: } \\
\text { - Third parties (other than government utility) } \\
\text { cannot sell recycled water to companies in } \\
\text { Victoria (Giurco et al., 2011) } \\
\text { Technical drivers: } \\
\text { - Water quality requirements for receiving } \\
\text { companies (Giurco et al., 2011) } \\
\text { Uncertainty around quality tolerances for input } \\
\text { water (Giurco et al., 2011) }\end{array}$ \\
\hline
\end{tabular}

\section{DISCUSSION}

The reclamation, treatment and reuse of municipal wastewater can provide important environmental benefits. In this paper, 25 studies on this topic were reviewed and it was found that there are many $(>150)$ different drivers acting for and against wastewater recycling. To deal with the challenge of comparing studies that entailed different research designs, a framework was developed which allowed the literature to be organized into comparable study contexts. Studies were categorized according to the level of analysis (wastewater recycling scheme; city; water utility; state; country; global) and outcome investigated (development/investment in new schemes; program implementation; percentage of wastewater recycled; percentage of water demand covered by recycled water; multiple outcomes). Findings across comparable case studies were then grouped according to the type (for or against recycling) and category of driver (social, natural, technical, economic, policy or business). The utility of the framework is demonstrated by summarizing the findings from four Australian studies at the city-level. The framework offers a unique approach for disentangling the broad range of potential drivers for and against water recycling and to focus on those that seem relevant in specific study contexts. It may offer a valuable starting point for building hypotheses in future work. 
The overarching aim of this research was to consolidate the findings from previous literature investigating the drivers for and against water recycling. An analysis of 25 studies revealed over 150 drivers, and these furthermore appeared to differ depending on the research design. We argued that studies should only be compared if they are conducted at the same level of analysis and for the same outcome. Of the 25 studies analyzed, this criterion (Table 2) was only met by groups with a maximum of four studies. It would be advantageous to undertake further comparative research to provide additional insights into the viability of water recycling across different study contexts. As discussed in the introduction, such knowledge is important for prioritizing investments in new recycling schemes.

From analyzing the research designs across the 25 previous studies, a notable similarity was an emphasis on single case studies and the use of a qualitative approach to data analysis. An advantage of a small-N research design is that the researcher can obtain a deep understanding of the specific case to ensure that the most important drivers of system behavior are included in analysis. This is obviously crucial, as the specific local setting (history, values, economic and political situation) can strongly influence wastewater recycling outcomes. However, a major disadvantage of detailed analyses of single cases lies in having a limited ability to generalize to other study contexts. Only three of the 25 surveyed articles included more than 20 cases (Bischel et al., 2012; Bixio et al., 2006; Lazarova et al., 2000). While we acknowledge the value of qualitative analyses of single cases, we encourage the use of large$\mathrm{N}$ research designs in future work.

Several of the reviewed studies incorporated an intermediate-N number of cases, and many of them relied on a qualitative or descriptive approach to analysis. These studies differed in their objectives, including analyzing the factors that influence decisions to invest in recycling schemes (Institute for Sustainable Futures, 2013), understanding operational issues faced when running reuse schemes (Muston and Wille, 2006), identifying contextual conditions associated with insufficient water availability and therefore reuse (Hochstrat, 2008), and describing details of specific water recycling schemes and how they have contributed to increased recycling country-level (Apostolidis et al., 2011). Conventional statistical approaches would not have been appropriate for meeting these diverse research objectives, resulting in a challenge for systematically drawing conclusions across cases (Fiss, 2007). One approach that can address this limitation is the technique of Qualitative Comparative Analysis (QCA), which aims to bridge the benefits of small-N and large-N research designs (Rihoux and Ragin, 2009). Incorporating Boolean algebra and set theory, QCA searches for the minimal combinations of necessary and/or sufficient conditions that are associated with a given outcome of interest (Vis, 2012). Recently (Kunz et al., 2015), we applied QCA to investigate water recycling performance (measured as the percentage of wastewater recycled) among 25 water utilities in New South Wales, Australia. We found QCA to be a valuable approach for untangling the complex drivers for and against recycling, and therefore recommend that it be given due consideration for future research on this topic.

An additional aim of this paper was to consider the context and conditions under which some drivers seem to be more important than others. The proposed framework proved useful for organizing studies into comparable study contexts and subsequently offered a basis to further synthesize study findings. The framework also allows researchers to deal with the high number of potential drivers. Using the framework, we were able to delimit the $>150$ influential drivers into a smaller subset of seven drivers for, and seven drivers against, recycling that were relevant for the specific study context of developing and/or investing in new recycling schemes within cities. 
Further elaboration of the framework could be worthwhile. In particular, the framework currently draws distinctions based only on two aspects of the study design (i.e. the level of analysis and the outcome investigated). Future work might consider additional aspects such as the end user of recycled water, which was found to influence water recycling in recent work (Kunz et al., 2015). The papers reviewed here similarly showed that industrial reuse is influenced by business-related drivers (e.g. security of water supply, cost of recycled water) (Giurco et al., 2011) while agricultural reuse in Italy was found to be mainly constrained by restrictive regulation (Barbagallo et al., 2001). The type of beneficial use was excluded from our current framework because only six of the 25 studies considered water reuse for individual end uses (Table 1).

We suggest that our framework, which we developed to organize findings from previous research (Figure 1), may offer a valuable starting point for future work through framing new hypotheses according to the scale of analysis and outcome examined. Future research should also acknowledge that drivers differ according to whether they act for or against recycling and that several categories of driver (natural, social, economic, business, policy and technical) can be influential. These should be explicitly studied in future research. Although not considered here, the role of individual actors and institutions may be significant and could be examined in future studies. Socio-political context has been shown to play a crucial role in transitioning towards sustainable urban water management practices (Brown et al., 2009; Ferguson et al., $2013 b$ ), but it has only recently been given explicit attention in water recycling studies (Bischel et al., 2012; Harris-Lovett et al., 2015). While many of the 25 studies in this review acknowledged the importance of regulatory changes and historical conditions (see Table S4 of the Supplementary Material), very few included an extensive sociological or political analysis. For example, policy process analysis (Sabatier and Weible, 2014) offers a toolbox for analyzing the influence of policy preferences and power of individuals and collective actors, and their networking, negotiating, framing and coalition building activities within different institutional contexts on actual policy outcomes.

Although there has been considerable research on the topic of water recycling, our review revealed few attempts to define explicitly the complex array of drivers that promote/hinder reuse. In the course of our review of 25 studies, we identified numerous combinations of level of analysis and outcome examined that have, as yet, been unexplored (Table 2) and thus offer opportunities for further research.

\section{ACKNOWLEDGEMENTS}

The authors are grateful to colleagues from Eawag and representatives from The University of Queensland, the Australian Water Recycling Centre of Excellence, CSIRO Land and Water, The Institute for Sustainable Futures, the NSW Office of Water, and SA Water who provided expert insights throughout this research project. R. Hochstrat and C. Kazner (Fachhochschule Nordwestschweiz) provided valuable insights about the application of water reuse in the European context and the benefits of comparative research in the area of water recycling. The hierarchical representation of the urban water system was inspired by discussions with C.J. Moran, J. Keller and Z. Yuan (University of Queensland). This work was supported by internal project funding from Eawag. The work also benefited from a travel grant from the Swiss National Science Foundation. 


\section{REFERENCES:}

Allen, T.F.H., Starr, T.B., 1982. Hierarchy: Perspectives for Ecological Complexity. The University of Chicago Press, Chicago and London.

Anderson, J.M., 2006. Integrating recycled water into urban water supply solutions. Desalination 187, 1-9.

Apostolidis, N., Hertle, C., Young, R., 2011. Water Recycling in Australia. Water 3, 869-881.

Arbon, M., Ireland, M., 2003a. Water recycling: a major new initiative for Melbourne crucial for a sustainable future. Water Science and Technology 47, 57-63.

Arbon, M., Ireland, M., 2003b. Water recycling: a major new initiative for Melbourne--crucial for a sustainable future. Water science and technology : a journal of the International Association on Water Pollution Research 47, 57-63.

Asano, T., 2005. Urban water recycling. Water science and technology : a journal of the International Association on Water Pollution Research 51, 83-89.

Australian Bureau of Statistics, 2011. 1259.0.30.001 - Australian Standard Geographical Classification (ASGC) Digital Boundaries, Australia, July 2011, in: Australian Bureau of Statistics (Ed.).

Barbagallo, S., Cirelli, G.L., Indelicato, S., 2001. Wastewater reuse in Italy. Water science and technology : a journal of the International Association on Water Pollution Research 43, 43-50.

Bischel, H.N., Simon, G.L., Frisby, T.M., Luthy, R.G., 2012. Management Experiences and Trends for Water Reuse Implementation in Northern California. Environmental Science \& Technology 46, 180-188.

Bixio, D., Thoeye, C., De Koning, J., Joksimovic, D., Savic, D., Wintgens, T., Melin, T., 2006. Wastewater reuse in Europe. Desalination 187, 89-101.

Brown, R.R., Keath, N., Wong, T.H.F., 2009. Urban water management in cities: historical, current and future regimes. Water Science and Technology 59, 847-855.

Chanan, A., Vigneswaran, S., Kandasamy, J., 2010. Valuing stormwater, rainwater and wastewater in the soft path for water management: Australian case studies. Water Science and Technology 62, 2854-2861.

Chanan, A.P., Vigneswaran, S., Kandasamy, J., Simmons, B., 2011. Lessons for a viable water recycling industry. Proceedings of the Institution of Civil Engineers-Water Management 164, 213-219.

Chang, D., Ma, Z., Wang, X., 2013. Framework of wastewater reclamation and reuse policies (WRRPs) in China: Comparative analysis across levels and areas. Environmental Science \& Policy 33, 41-52.

Chen, Z., Huu Hao, N., Guo, W., 2013. A Critical Review on the End Uses of Recycled Water. Critical Reviews in Environmental Science and Technology 43, 1446-1516. 
Department of Energy and Water Supply, 2013. Queensland's water sector: a 30-year strategy.

Department of Primary Industries, O.o.W., 2006. NSW Implementation Plan for the National Water Initative. New South Wales Government,

Environment and Sustainable Development, 2013. Water for the future - striking the balance: Draft ACT Water Strategy 2013. ACT Government, Environment and Sustainable Development, Canberra.

Ferguson, B.C., Brown, R.R., Deletic, A., 2013a. Diagnosing transformative change in urban water systems: Theories and frameworks. Global Environmental Change 23, 264-280.

Ferguson, B.C., Brown, R.R., Frantzeskaki, N., de Haan, F.J., Deletic, A., 2013b. The enabling institutional context for integrated water management: Lessons from Melbourne. Water Research 47, 7300-7314.

Fiss, P.C., 2007. A set-theoretic approach to organizational configurations. Academy of Management Review 32, 1180-1198.

Freeman, S., Bates, J., Wallis-Lage, C., McEvoy, J., 2008. Drought relief in South East, Queensland, Australia, provided by membrane-reclaimed water. Journal American Water Works Association 100, 40-+.

GHD, 2012. City of Sydney - Recycled Water Plan.

Giurco, D., Bossilkov, A., Patterson, J., Kazaglis, A., 2011. Developing industrial water reuse synergies in Port Melbourne: cost effectiveness, barriers and opportunities. Journal of Cleaner Production 19, 867-876.

Harris-Lovett, S.R., Binz, C., Sedlak, D.L., Kiparsky, M., Truffer, B., 2015. Beyond User Acceptance: A Legitimacy Framework for Potable Water Reuse in California. Environmental Science \& Technology 49, 7552-7561.

Hermanowicz, S.W., Diaz, E.S., Coe, J., 2001. Prospects, problems and pitfalls of urban water reuse: a case study. Water Science and Technology 43, 9-16.

Hochstrat, R., Wintgens, T., Kazner, C., Melin, T., Gebel, J., 2010. Options for water scarcity and drought management-the role of desalination. Desalination and Water Treatment 18, 96102.

Hochstrat, R., Wintgens, T., Melin, T., 2008. Development of integrated water reuse strategies. Desalination 218, 208-217.

Hochstrat, R., Wintgens, T., Melin, T., Jeffrey, P., 2006. Assessing the European wastewater reclamation and reuse potential - a scenario analysis. Desalination 188, 1-8.

Hurlimann, A., Dolnicar, S., 2010. When public opposition defeats alternative water projects The case of Toowoomba Australia. Water Research 44, 287-297.

Institute for Sustainable Futures, 2013. Policy settings, regulatory frameworks and recycled water schemes, Building industry capability to make recycled wtaer investment decisions. 
Prepared by the Institute for Sustaianble Futures, University of Technology, Sydney for the Australian Water Recycling Centre of Excellence.

Kracman, B., Martin, R., Sztajnbok, P., 2001. The Virginia pipeline: Australia's largest water recycling project. Water Science and Technology 43, 35-42.

Kunz, N.C., Fischer, M., Ingold, K., Hering, J.G., 2015. Why Do Some Water Utilities Recycle More than Others? A Qualitative Comparative Analysis in New South Wales, Australia. Environmental Science \& Technology.

Kunz, N.C., Moran, C.J., Kastelle, T., 2013. Implementing an integrated approach to water management by matching problem complexity with management responses: a case study of a mine site water committee. Journal of Cleaner Production 52, 362-373.

Lazarova, V., Cirelli, G., Jeffrey, P., Salgot, M., Icekson, N., Brissaud, F., 2000. Enhancement of integrated water management and water reuse in Europe and the Middle East. Water Science and Technology 42, 193-202.

Marsden Jacob Associates, 2008. National snapshot of current and planned water recycling and reuse rates. Final Report prepared for the Department of the Environment, Water, Heritage and the Arts, Melbourne.

Moran, C.J., Kunz, N.C., 2014. Sustainability as it pertains to minerals and energy supply and demand: a new interpretative perspective for assessing progress. J. Clean Prod. 84, 16-26.

Muston, M.H., Wille, A., 2006. Operator experience with recycling in Australia. Desalination $188,43-50$.

Ostrom, E., 2007. A diagnostic approach for going beyond panaceas. Proc. Natl. Acad. Sci. U. S. A. $104,15181-15187$.

Radcliffe, J.C., 2006. Future directions for water recycling in Australia. Desalination 187, 7787.

Radcliffe, J.C., 2010. Evolution of water recycling in Australian cities since 2003. Water Science and Technology 62, 792-802.

Rihoux, B.; Ragin, C. C. 2009. Configurational comparative methods: Qualitative comparative analysis (QCA) and related techniques; Sage Publications, Inc.: United States of America.

Sabatier, P.A., Weible, C.M., eds. 2014. Theories of the Policy Process. Boulder CO: Westview Press.

Salthe, S.N., 1985. Evolving hierarchical systems: their structure and representation. Columbia University Press New York.

Traves, W.H., Gardner, E.A., Dennien, B., Spiller, D., 2008. Towards indirect potable reuse in South East Queensland. Water Science and Technology 58, 153-161. 
van Beers, D., Bossilkov, A., Corder, G., van Berkel, R., 2007a. Industrial Symbiosis in the Australian Minerals Industry: The Cases of Kwinana and Gladstone. Journal of Industrial Ecology 11, 55-72.

van Beers, D., Corder, G., Bossilkov, A., van Berkel, R., 2007b. Industrial symbiosis in the Australian minerals industry - The cases of Kwinana and Gladstone. Journal of Industrial Ecology 11, 55-72.

Vis, B., 2012. The Comparative Advantages of fsQCA and Regression Analysis for Moderately Large-N Analyses. Sociological Methods \& Research 41, 168-198.

Yüce, S., Kazner, C., Hochstrat, R., Wintgens, T., Melin, T., 2012. Water reuse versus seawater desalination - evaluation of the economic and environmental viability, in: Lazarova, V., Choo, K., Cornel, P. (Eds.), Water-Energy Interactions of Water Reuse. IWA Publishing, pp. 243-256. 